\title{
The climate impact of past changes in halocarbons and CO2in the tropical UTLS region
}

Article

Published Version

McLandress, C., Shepherd, T. G., Reader, M. C., Plummer, D. A. and Shine, K. P. (2014) The climate impact of past changes in halocarbons and CO2in the tropical UTLS region. Journal of Climate, 27 (23). pp. 8646-8660. ISSN 1520-0442 doi: https://doi.org/10.1175/JCLI-D-14-00232.1 Available at https://centaur.reading.ac.uk/37276/

It is advisable to refer to the publisher's version if you intend to cite from the work. See Guidance on citing.

Published version at: http://dx.doi.org/10.1175/JCLI-D-14-00232.1

To link to this article DOI: http://dx.doi.org/10.1175/JCLI-D-14-00232.1

Publisher: American Meteorological Society

All outputs in CentAUR are protected by Intellectual Property Rights law, including copyright law. Copyright and IPR is retained by the creators or other copyright holders. Terms and conditions for use of this material are defined in the End User Agreement.

www.reading.ac.uk/centaur 
Central Archive at the University of Reading

Reading's research outputs online 


\title{
The Climate Impact of Past Changes in Halocarbons and $\mathrm{CO}_{2}$ in the Tropical UTLS Region
}

\author{
ChARLES MCLANDRESS \\ Department of Physics, University of Toronto, Toronto, Ontario, Canada \\ THEODORE G. SHEPHERD \\ Department of Meteorology, University of Reading, Reading, United Kingdom \\ M. CATHERINE READER \\ University of Victoria, Victoria, British Columbia, Canada \\ DAVID A. Plummer \\ Canadian Centre for Climate Modelling and Analysis, Victoria, British Columbia, Canada \\ KEITH P. SHINE \\ Department of Meteorology, University of Reading, Reading, United Kingdom
}

(Manuscript received 26 March 2014, in final form 11 July 2014)

\begin{abstract}
A chemistry-climate model coupled to an ocean model is used to compare the climate impact of past (19602010) changes in concentrations of halocarbons with those of $\mathrm{CO}_{2}$ in the tropical upper troposphere and lower stratosphere (UTLS). The halocarbon contribution to both upper troposphere warming and the associated increase in lower stratospheric upwelling is about $40 \%$ as large as that due to $\mathrm{CO}_{2}$. Trends in cold-point temperature and lower stratosphere water vapor are positive for both halocarbons and $\mathrm{CO}_{2}$, and are of about the same magnitude. Trends in lower stratosphere ozone are negative, due to the increased upwelling. These increases in water vapor and decreases in lower stratosphere ozone feed back onto lower stratosphere temperature through radiative cooling. The radiative cooling from ozone is about a factor of 2 larger than that from water vapor in the vicinity of the cold-point tropopause, while water vapor dominates at heights above $50 \mathrm{hPa}$. For halocarbons this indirect radiative cooling more than offsets the direct radiative warming, and together with the adiabatic cooling accounts for the lack of a halocarbon-induced warming of the lower stratosphere. For $\mathrm{CO}_{2}$ the indirect cooling from increased water vapor and decreased ozone is of comparable magnitude to the direct warming from $\mathrm{CO}_{2}$ in the vicinity of the cold-point tropopause, and (together with the increased upwelling) lowers the height at which $\mathrm{CO}_{2}$ increases induce stratospheric cooling, thus explaining the relatively weak increase in cold-point temperature due to the $\mathrm{CO}_{2}$ increases.
\end{abstract}

\section{Introduction}

Halocarbons are potent greenhouse gases (GHGs) because they interact strongly with infrared radiation in the $8-13-\mu \mathrm{m}$ atmospheric window. Present-day

\footnotetext{
Corresponding author address: Charles McLandress, Department of Physics, University of Toronto, 60 St. George St., Toronto, ON M5S 1A7, Canada.

E-mail: charles@atmosp.physics.utoronto.ca
}

concentrations of halocarbons are optically thin. In clear skies, this allows outgoing infrared radiation emitted by the surface and lower troposphere to reach the middle and upper troposphere where it is absorbed and reemitted at a lower temperature, causing a net convergence of radiative flux, and hence warming. The warming peaks at the tropical tropopause where temperatures depart most strongly from the surface. Although the anthropogenic emission of $\mathrm{CO}_{2}$ is the dominant contributor to middle tropospheric and surface warming, 
the fact that $\mathrm{CO}_{2}$ cools the stratosphere means that $\mathrm{CO}_{2-}$ induced temperature trends in the upper troposphere and lower stratosphere (UTLS) are small and their sign is uncertain. Since halocarbons warm the troposphere and lower stratosphere, they could therefore have as large an impact on the UTLS as $\mathrm{CO}_{2}$.

The importance of halocarbons as significant GHGs was first discussed by Ramanathan (1975), and subsequently Ramanathan et al. (1987) firmly established their contribution to radiative forcing. Forster and Joshi (2005) estimated that the direct radiative effect of halocarbons contributed a warming of the tropical tropopause of approximately $0.4 \mathrm{~K}$ over the past 50 years, dominating the effect of increases in other well-mixed GHGs. The most recent estimates indicate that the radiative forcing from halocarbons since 1960 is approximately $0.30 \mathrm{~W} \mathrm{~m}^{-2}$, which is about $30 \%$ of that due to $\mathrm{CO}_{2}$ over the same period (Stocker et al. 2014). In spite of their important role in radiative forcing, there has been virtually no work done to assess the radiative impact of halocarbons on climate, which necessarily requires the use of sophisticated climate models capable of simulating the feedbacks between radiation, atmospheric constituents, and dynamics. Although several studies have separated the effects of GHG increases and ozone depletion on climate (e.g., McLandress et al. 2010; Plummer et al. 2010), the radiative effects of the halocarbons were always included in the GHG forcing following the Stratospheric Processes and their Role in Climate (SPARC) Chemistry-Climate Model (CCM) Validation (CCMVal) activity experimental protocols (Eyring et al. 2008). In fact, apart from Forster and Joshi (2005), the only other modeling study we are aware of that examined in any detail the separate climate impact of halocarbons is that of Dickinson et al. (1978), who showed that they caused a warming of the tropical upper troposphere that exceeded that at the surface by a factor of 2. While their focus was on the troposphere, they (and Forster and Joshi 2005) also suggested that a halocarbon-induced warming of the tropical tropopause region could result in a moistening of the lower stratosphere, which could in turn result in a decrease of stratospheric ozone, and also impact the radiative balance. However, the model they used was unsuitable for examining such feedbacks [the radiative impact seems to have been first modeled in any detail by Stuber et al. (2001) although in a slightly different context and using highly idealized gas perturbations]. Wang et al. (1991) also pointed to the differences in UTLS responses between $\mathrm{CO}_{2}$-only calculations and those including a number of other GHGs (including halocarbons) but they did not specifically isolate the halocarbon component.
The study of Dickinson et al. (1978) highlights the fact that the stratospheric radiative impacts of halocarbon increases, and indeed of $\mathrm{CO}_{2}$ increases, include not only their direct radiative effects but also their indirect radiative effects associated with changes in water vapor and ozone. Contributing to these indirect effects are possible increases in tropical upwelling, which can be generally expected to result from tropospheric warming (e.g., McLandress and Shepherd 2009). In recent years, there has been growing interest in the tropical UTLS as a sensitive region for chemistry-climate coupling (e.g., Gettelman et al. 2010). It has been generally assumed that past changes in this region have mainly resulted from increases in well-mixed GHGs, but if a significant fraction of those changes is due to halocarbons, then this has implications for future changes.

The goal of this paper is therefore to quantify the climate impact of past changes in halocarbons, in particular chlorofluorocarbons (CFCs) and their substitutes, on the UTLS, and to compare them with those of $\mathrm{CO}_{2}$. A proper examination of these effects necessarily requires a stratosphere-resolving CCM that is coupled to an ocean model. The latter ensures a physically realistic tropospheric response to the tropospheric warming, while the former ensures a physically realistic stratospheric response including feedbacks on water vapor and ozone. We do this using a set of transient simulations from a coupled version of the Canadian Middle Atmosphere Model (CMAM), a CCM that extends up to the lower thermosphere. The climate impacts of halocarbons and $\mathrm{CO}_{2}$ are isolated by differencing simulations in which their concentrations are separately held fixed in time in the radiation scheme and control simulations in which their concentrations evolve transiently. We focus on the period from 1960 to the present since that is when the effects of halocarbons are strongest and the prescribed tropospheric abundances of halocarbons and other well-mixed GHGs are constrained by observations. We furthermore focus on the tropical UTLS since that is the region of the atmosphere where the effects of halocarbons are expected to be the strongest relative to $\mathrm{CO}_{2}$, and is also where the coupling between radiation and dynamics is most complex. To separate the direct and indirect radiative effects of the different gases we perform offline radiative transfer calculations.

\section{Model and simulations}

\section{a. Model}

CMAM is a coupled CCM used to simulate the effects of stratospheric ozone depletion (and recovery) and 
climate change. It is the upward extension of the Canadian Centre for Climate Modelling and Analysis (CCCma) third-generation coupled general circulation model (CGCM3), which was used for the Intergovernmental Panel on Climate Change's (IPCC's) Fourth Assessment Report (Solomon et al. 2007). The coupled version of CMAM used here was used in the 2010 World Meteorological Organization (WMO) Ozone Assessment (WMO 2011) and was the only one of the CCMs used there to be coupled to a dynamic ocean model. The atmospheric component of CMAM has 71 vertical levels extending from the surface to approximately $100 \mathrm{~km}$, with a resolution of about $1.1 \mathrm{~km}$ in the UTLS region. In the horizontal direction a triangularly truncated resolution of T31 is used in the present runs, corresponding to a grid size of about $6^{\circ}$ in latitude and longitude. Descriptions of both the atmospheric and oceanic components of CMAM are provided in Scinocca et al. (2008) and McLandress et al. (2010), respectively, and references therein.

Longwave (LW) radiation in the troposphere and lower stratosphere is treated using the Morcrette (1991) scheme. (A different LW scheme is used in the upper stratosphere and mesosphere, but is not discussed here since it is above the region of interest.) The scheme employs six wavenumber bands and accounts for the effects of well-mixed GHGs $\left(\mathrm{CO}_{2}, \mathrm{CH}_{4}, \mathrm{~N}_{2} \mathrm{O}, \mathrm{CFC}-11\right.$, and $\mathrm{CFC}-12$ ), water vapor, and ozone. The concentration of CFC-11 is inflated to account for the radiative forcing of the many minor species not explicitly included in the radiation scheme: all species controlled under the Montreal Protocol (except CFC-12, which is included separately) and many of the perfluorinated compounds (PFCs), hydrofluorocarbons (HFCs), and $\mathrm{SF}_{6}$ listed in Table 2.14 of Solomon et al. (2007). While $\mathrm{SF}_{6}$ has been included, its radiative impact over the recent past is very small (Stocker et al. 2014). The inflated concentration of CFC-11 used in the radiation scheme, denoted as CFC-11*, is calculated as the sum of the concentration of the individual species weighted by the relative radiative efficiency to CFC-11 as given in Table 2.14 of Solomon et al. (2007). Absorption by these different gases is near the optically thin limit, allowing absorption to be combined linearly. CFC-11 and CFC-12, which we explicitly include, contribute about two-thirds of the total forcing of these minor species in 2011 (Stocker et al. 2014), and the use of CFC-11* accounts for the remaining third. Linear scaling of the minor halocarbons by the radiative efficiency is, in fact, the approach used in the IPCC assessment reports to calculate the contribution of these minor gases to radiative forcing. We also note that the lumping together of different halocarbons like this is commonly used in climate models to account for the radiative forcing of minor species not explicitly included in the model radiation scheme (J. Cole 2014, personal communication). More directly applicable to the lower stratospheric response, the results of Myhre and Stordal (1997, their Table 10) indicate that the difference between the instantaneous forcing and the stratosphere-temperature-adjusted forcing (which is a proxy for the impact of the gases on lower stratospheric temperature changes) is $7.6 \%$ for CFC- 11 , $9.4 \%$ for $\mathrm{CFC}-12$, and $8.3 \%$ for both $\mathrm{CFC}-113$ and HCFC-22 (the two gases that contribute most of the halocarbon forcing after CFC-11 and CFC-12), and in fact almost all halocarbons lie in the range of $6 \%-10 \%$. Hence we have good reason to believe that the use of the CFC-11* proxy is not a major source of error. CFC$11^{*}$ and $\mathrm{CFC}-12$ thus constitute the halocarbons that are used in these simulations. Prescribed, spatially uniform values are assumed for $\mathrm{CO}_{2}, \mathrm{CH}_{4}, \mathrm{~N}_{2} \mathrm{O}, \mathrm{CFC}$ $11^{*}$, and CFC-12, while water vapor and ozone are prognostic model variables. The well-mixed assumption for $\mathrm{CO}_{2}, \mathrm{CH}_{4}, \mathrm{~N}_{2} \mathrm{O}$, and CFCs is often assumed in radiative transfer calculations. The influence of departures from spatial homogeneity on tropopause radiative forcing for $\mathrm{CH}_{4}$ and CFCs, which are shorter lived (and hence more inhomogeneous) than $\mathrm{N}_{2} \mathrm{O}$, has been estimated to be only few percent (Freckleton et al. 1998). We note that above the tropopause, CFC11 and CFC-12, as well as many of the other species making up CFC-11*, depart markedly from a constant vertical profile (e.g., Kellmann et al. 2012), but for our focus on the tropical UTLS the well-mixed assumption is adequate.

\section{b. Simulations}

Four sets of transient simulations, which were devised more than five years ago for the interpretation of experiments performed for the second phase of SPARC CCMVal (CCMVal2), are used here. Although each extends from 1960 to 2099, we focus only on the first $50 \mathrm{yr}$. The first set is the REF-B2 reference simulation that was analyzed extensively in SPARC CCMVal (2010). It comprises an ensemble of three members using time-varying concentrations for GHGs, which are specified according to the IPCC Special Report on Emission Scenarios (SRES) moderate A1B scenario (Houghton et al. 2001), and ozone depleting substances (ODSs). Figure 1 shows the concentrations of CFC-11*, CFC-12, and $\mathrm{CO}_{2}$ used in the radiation scheme in the REF-B2 simulation, plotted only up to 2010. For comparison, the concentration of CFC-11 is also shown. As expected, it is more than a factor of 2 weaker than CFC-11* because of the relatively large cumulative contribution of the minor species beyond CFC-11 and CFC-12. The inclusion of the CFC substitutes explains why the 


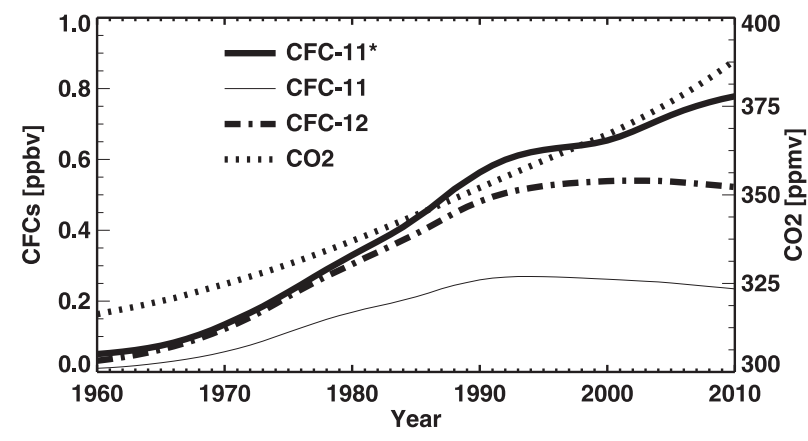

FIG. 1. Time series of concentration per unit volume of halocarbons (CFC-11*, CFC-11, and CFC-12) and $\mathrm{CO}_{2}$ used in the radiation scheme in the REF-B2 and GHG simulations. See text for explanation of the meaning of CFC-11*.

concentration of CFC-11* increases up to (and beyond) 2010, while that of CFC-11 and CFC-12 peak in the 1990s and decline thereafter in accordance with the Montreal Protocol. Since the SRES A1B scenario was devised over a decade ago, the last few years of the twentieth century and the first decade of this century are not based on observations. However, the differences between the scenario and the observations over this time period are not substantial, particularly for $\mathrm{CO}_{2}$ and the halocarbons.

The second simulation is identical to REF-B2 but with the concentration of $\mathrm{CO}_{2}$ held fixed in time at 1960 levels. It will be referred to as the "fixed $\mathrm{CO}_{2}$ " simulation and consists of only a single member. The third simulation, another ensemble of three, uses transiently varying concentrations of GHGs in the radiation schemes, as in REF-B2, but with the concentrations of ODSs held fixed at 1960 levels in the chemistry scheme. This is the SCN-B2b simulation described in Eyring et al. (2008), which we will refer to here as the GHG simulation. The fourth and final simulation is identical to the GHG simulation, but with the concentrations of halocarbons held fixed at 1960 levels in both the chemistry and radiation schemes. It will be referred to as the "fixed halocarbon" simulation (with the understanding that the ODS concentrations are also fixed) and consists of only a single member. For reference, the four sets of simulations, along with their defining characteristics, are listed in Table 1. Further discussion of the setup of the REF-B2 and GHG simulations can be found in McLandress et al. (2010).

The separate climate impacts of halocarbons and $\mathrm{CO}_{2}$ are determined by differencing the two pairs of simulations: 1) GHG minus fixed halocarbon, yielding the climate impact of halocarbons, and 2) REF-B2 minus fixed $\mathrm{CO}_{2}$, yielding the climate impact of $\mathrm{CO}_{2}$. It should be stressed that although the four simulations include the transient effects of chemistry, those effects will cancel out to first order when the differences are computed, leaving only the transient radiative effects of halocarbons and $\mathrm{CO}_{2}$. Note that for the REF-B2 and GHG simulations ensemble averages are used.

As a consequence of an intercomparison of climate model radiative transfer codes for the IPCC Fourth Assessment Report (Collins et al. 2006), it was found that the LW absorption cross-sections for halocarbons in CGCM3 were too large by a factor of 2.5. This means that the heating rates due to halocarbons are overestimated by a factor of about 2.5 in our simulations, as is demonstrated in appendix A using offline radiative transfer calculations. The overestimation of the halocarbon heating is corrected a posteriori by scaling the halocarbon-induced trends in all geophysical quantities by a factor of 0.4 (i.e., 1/2.5).

Inherent in our scaling of the halocarbon-induced trends is the underlying assumption that the response to the heating is linear. We believe this to be a valid approximation for several reasons. First, the anthropogenic change in heating is generally small in comparison to the background total LW heating. Second, since we are scaling down the signal, not up, the range of heating rates represented by the scaling is already present in our simulations. Time series of tropical average sea surface temperature (Fig. 2b) increase approximately linearly with time, so the linear increase with time also found (results not shown) in lower stratosphere water vapor and ozone (or decrease in the case of ozone), within the considerable noise of interannual variability, suggests that the response to surface warming (and hence halocarbon forcing) is linear to a good first approximation.

TABLE 1. List of simulations and the corresponding time variation of the gases used in the radiation and chemistry schemes. Transient means the prescribed gas concentrations at the lower boundary vary from 1960 to 2100; fixed means they are held constant at 1960 levels. The climate impacts of $\mathrm{CO}_{2}$ and halocarbons are obtained by differencing the REF-B2 and fixed- $\mathrm{CO}_{2}$ simulations and the GHG and fixedhalocarbon simulations, respectively.

\begin{tabular}{lcccccc}
\hline $\begin{array}{c}\text { Name of } \\
\text { simulation }\end{array}$ & $\begin{array}{c}\text { No. of } \\
\text { members }\end{array}$ & $\begin{array}{c}\mathrm{CO}_{2} \\
\text { (radiation) }\end{array}$ & $\begin{array}{c}\text { Halocarbons } \\
\text { (radiation) }\end{array}$ & $\begin{array}{c}\mathrm{N}_{2} \mathrm{O}, \mathrm{CH}_{4} \\
\text { (radiation) }\end{array}$ & $\begin{array}{c}\mathrm{ODSs} \\
\text { (chemistry) }\end{array}$ & $\begin{array}{c}\mathrm{N}_{2} \mathrm{O}, \mathrm{CH}_{4} \\
\text { (chemistry) }\end{array}$ \\
\hline REF-B2 & 3 & Transient & Transient & Transient & Transient & Transient \\
Fixed-CO & 1 & Fixed & Transient & Transient & Transient & Transient \\
GHG & 3 & Transient & Transient & Transient & Fixed & Transient \\
Fixed- halocarbon & 1 & Transient & Fixed & Transient & Fixed & Transient \\
\hline
\end{tabular}


(a)

$20^{\circ} \mathrm{S}-20^{\circ} \mathrm{N} 250 \mathrm{hPa}$

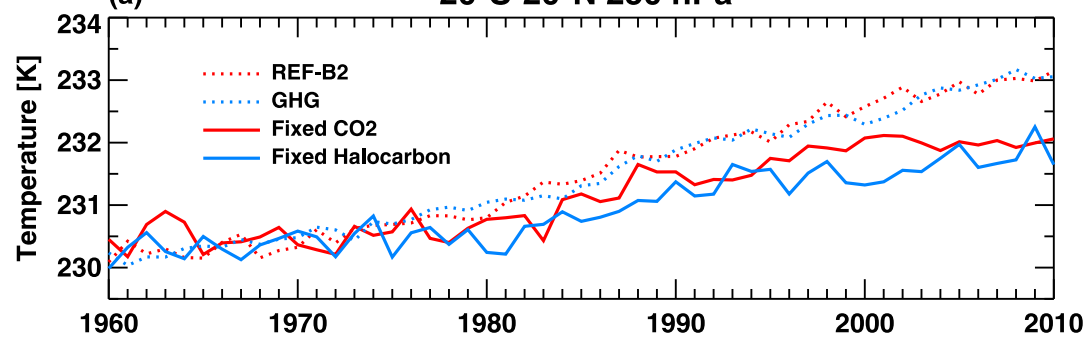

(b)

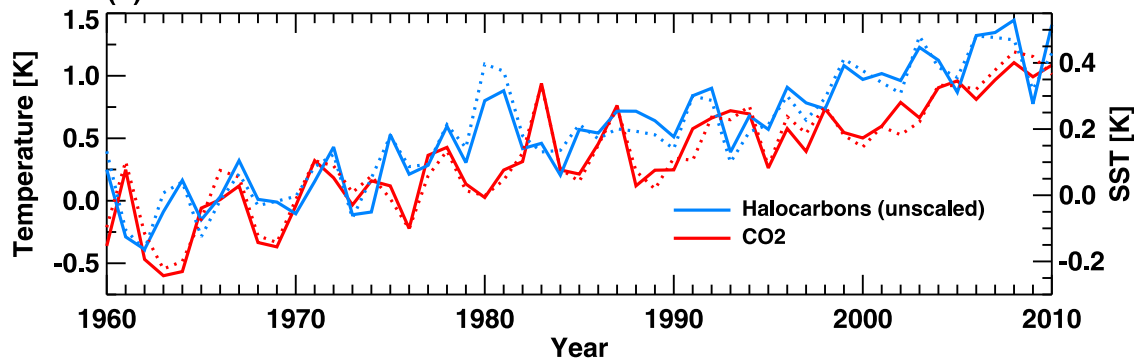

FIG. 2. Time series of annual mean tropical average temperature at $250 \mathrm{hPa}$ : (a) REF-B2 (red dots), GHG (blue dots), fixed- $\mathrm{CO}_{2}$ (red solid), and fixed-halocarbon (blue solid) simulations; (b) differences between the GHG and fixed-halocarbon simulations (unscaled climate impact of halocarbons, which is 2.5 times larger than the actual impact as explained in the text; blue solid) and between the REF-B2 and fixed- $\mathrm{CO}_{2}$ simulations (climate impact of $\mathrm{CO}_{2}$; red solid). The dotted curves in the bottom panel are the corresponding SST differences. Ensemble averages for the REF-B2 and GHG simulations are plotted. Tropical average is from $20^{\circ} \mathrm{S}$ to $20^{\circ} \mathrm{N}$.

The LW heating rates for $\mathrm{CH}_{4}$ and $\mathrm{N}_{2} \mathrm{O}$ were also overestimated in these simulations due to too-large values for the absorption cross sections. However, since these are optically thick bands, constant correction factors do not exist. Consequently we cannot use these simulations to examine the climate impacts of $\mathrm{CH}_{4}$ and $\mathrm{N}_{2} \mathrm{O}$ on the UTLS region. Since the same overestimated heating rates were used in all simulations, the differences between simulations used to determine the climate impacts of halocarbons and $\mathrm{CO}_{2}$ are unaffected by this issue.

\section{Results}

All results have been interpolated from the model vertical grid onto the standard CCMVal2 pressure levels. In the UTLS region the two grids have very nearly the same vertical resolution. All results represent annual means. Where tropical averages are presented, these are for $20^{\circ} \mathrm{N}-20^{\circ} \mathrm{S}$. Linear trends are computed from 1960 to 2010. Trends computed from the differences between the GHG and fixed-halocarbon simulations (i.e., the halocarbon effect) have been corrected by the 0.4 scale factor, as discussed above.

\section{a. Temperature}

Figure 2a shows time series of tropical-average upper tropospheric $(250 \mathrm{hPa})$ temperatures for the four simulations.
As expected the REF-B2 and GHG simulations (dotted) have the strongest trends, with both exhibiting nearly the same amount of warming. (Recall that the only difference between the two sets of simulations is that the ODSs are held fixed at 1960s levels in the chemistry scheme in the GHG simulations.) The fixedhalocarbon and fixed- $\mathrm{CO}_{2}$ simulations (solid) exhibit similar warming but are weaker in magnitude. The solid curves in Fig. $2 b$ show the corresponding temperature differences between the GHG and fixed-halocarbon simulations (unscaled climate impact of halocarbons; blue) and between the REF-B2 and fixed- $\mathrm{CO}_{2}$ simulations (climate impact of $\mathrm{CO}_{2}$; red). Although both curves have nearly the same positive trend, the halocarbon-induced warming is too strong by a factor of 2.5 as discussed in section $2 b$. The dotted curves in Fig. 2b show the corresponding differences in tropical sea surface temperatures (SSTs) for the same pair of simulations. The close correspondence with the solid curves indicates that the SST changes are driving nearly all the upper tropospheric temperature changes in the tropics, as expected.

Henceforth, all figures include the 0.4 scaling factor applied to the halocarbon effect. Figure 3 shows vertical profiles of trends in tropical-average temperatures due to halocarbons (blue) and $\mathrm{CO}_{2}$ (red), with the inset showing a close up of the UTLS region. For future 


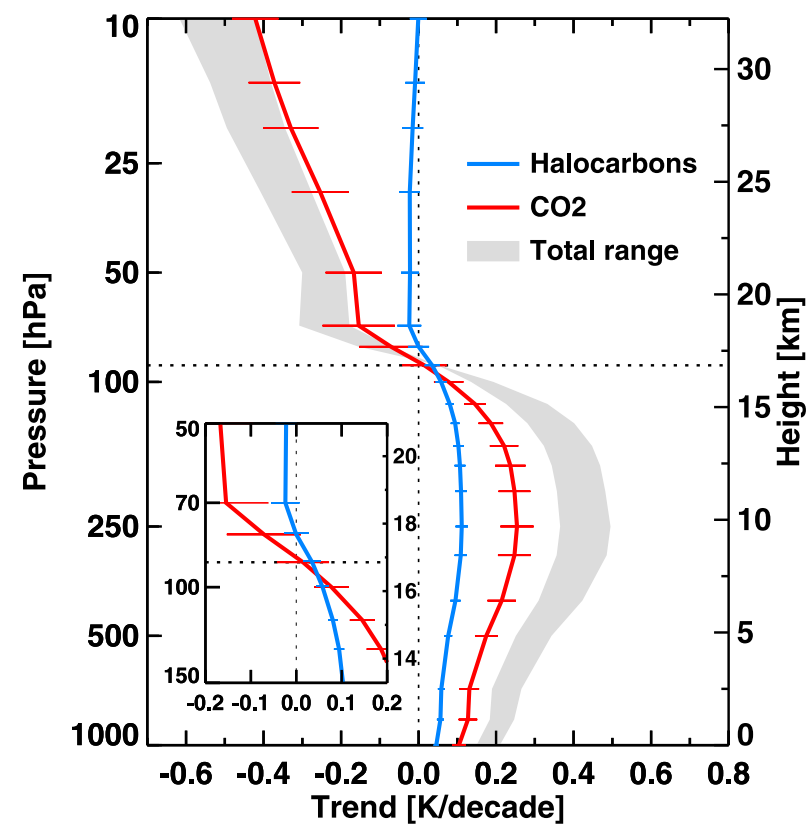

FIG. 3. Linear trends in annual mean tropical average temperature induced by halocarbons (blue) and $\mathrm{CO}_{2}$ (red). The gray shading denotes the total range of the temperature trends when all well-mixed GHGs and the chemical effects of transiently varying ODSs are included in the simulations; see text for details. Error bars denote the $95 \%$ confidence levels computed using a standard $t$ test assuming random and normally distributed residuals (as in all other figures). The inset is an enlargement of the halocarbonand $\mathrm{CO}_{2}$-induced trends in the tropopause region. The dotted horizontal line denotes the height of the climatological annual mean cold-point tropopause at the equator for the REF-B2 ensemble average. Note that in this and all subsequent figures the halocarbon-induced trends have been corrected by applying the scale factor of 0.4 . Tropical average is from $20^{\circ} \mathrm{S}$ to $20^{\circ} \mathrm{N}$. Trends are computed from 1960 to 2010. The right-hand axis is log-pressure height, computed using a 7-km scale height.

reference, the height of the cold-point tropopause in the model is also shown $(90 \mathrm{hPa}$, representing the model level with the lowest annual-mean temperature; horizontal dotted lines). The reason why the error bars ( $95 \%$ confidence levels) for the halocarbon-induced trends are substantially smaller than for the $\mathrm{CO}_{2}$ induced trends is because they have been scaled down by the factor of 0.4 , consistent with our assumption of the linearity of the response to the heating, which we have argued in section $2 \mathrm{~b}$ is valid. In other words, increasing the halocarbon radiative forcing by a factor of 2.5 in these simulations in the presence of the same natural variability has yielded a better signal-to-noise ratio and hence smaller relative uncertainties for the halocarbon-induced trends as compared to the $\mathrm{CO}_{2}$ induced trends.

As a result of the overestimation of the LW heating from $\mathrm{N}_{2} \mathrm{O}$ and $\mathrm{CH}_{4}$ (see section $2 \mathrm{~b}$ ), the tropospheric temperature trends due to halocarbons and $\mathrm{CO}_{2}$ cannot be compared to the temperature trends from all of the GHGs combined. To circumvent this problem we show a range of trends (gray shading) in Fig. 3, bounded in magnitude from below by the sum of the $\mathrm{CO}_{2^{-}}$and halocarbon-induced trends, and from above by the REF-B2 trend with the known error in the halocarbon heating rates removed. However, since the tropospheric upper bound is still an overestimate (it contains the overestimate of the warming from $\mathrm{N}_{2} \mathrm{O}$ and $\mathrm{CH}_{4}$ in the REF-B2 ensemble), the trend due to all GHGs would lie to the left of the tropospheric upper bound if a better representation of the radiative effects for $\mathrm{N}_{2} \mathrm{O}$ and $\mathrm{CH}_{4}$ had been used.

The halocarbon-induced trend shown in Fig. 3 peaks in the upper troposphere at $\sim 0.11 \mathrm{~K} \mathrm{decade}^{-1}$, which is slightly over $40 \%$ as large as the $\mathrm{CO}_{2}$-induced trend (see also Table 1). This percentage is somewhat higher than the value of $30 \%$ given earlier for the radiative forcing change over this period. Centered at $\sim 90 \mathrm{hPa}$ (i.e., in the vicinity of the cold-point tropopause) the halocarboninduced temperature trends exceed those of $\mathrm{CO}_{2}$, with the crossover from warming to cooling being distinctly higher for halocarbons than for $\mathrm{CO}_{2}$. This has important implications for stratospheric water vapor, as we shall see. In the stratosphere, $\mathrm{CO}_{2}$ and halocarbons both cause cooling, but with the effects of $\mathrm{CO}_{2}$ far outweighing those of halocarbons.

What is remarkable about Fig. 3 is the absence of warming in the lower stratosphere in the halocarboninduced trends, as would be expected to occur based solely on the halocarbon heating rates in Fig. A1b, which shows warming throughout this region (see also Forster et al. 1997). Clearly, adiabatic and other diabatic processes must be offsetting the LW warming from the halocarbon increase. As will be discussed shortly, this arises from increased tropical lower stratosphere upwelling and from increased radiative cooling and decreased radiative heating due to changes in water vapor and ozone, respectively. These same processes are also a part of the $\mathrm{CO}_{2}$-induced temperature trends.

Figure 4 shows zonal-mean temperature trends as a function of latitude and pressure induced by halocarbons and by $\mathrm{CO}_{2}$. The overall spatial structure of the two patterns is qualitatively similar in the troposphere, with halocarbons and $\mathrm{CO}_{2}$ both exhibiting maximum warming in the tropical upper troposphere, as expected from the lapse-rate feedback. Again, the largest relative impact of the halocarbons is in the tropical tropopause region where the halocarbon-induced warming extends higher than the $\mathrm{CO}_{2}$-induced warming, as seen by the vertical shift of the zero contour lines. Although it is not the subject of this study, the strong stratospheric cooling expected from increasing $\mathrm{CO}_{2}$, but not from increasing 
(a) Temp. Trend (Halocarbons)

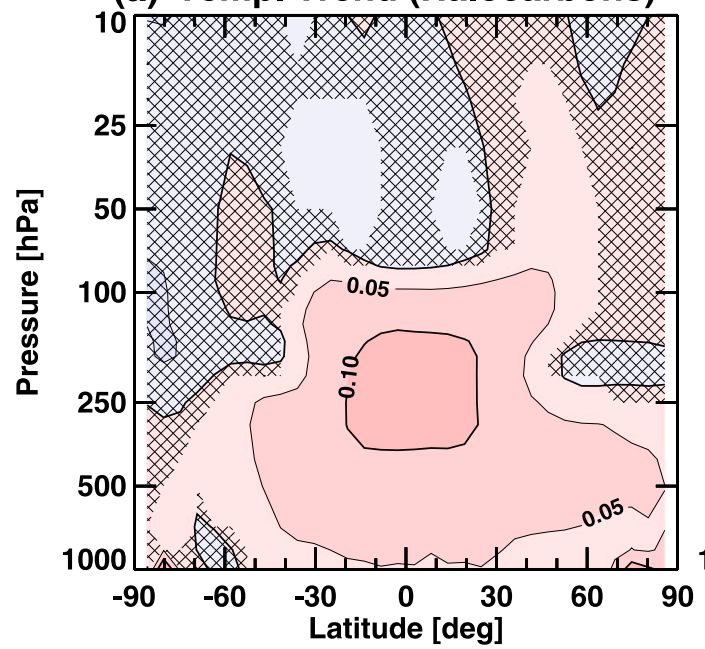

(b) Temperature Trend (CO2)

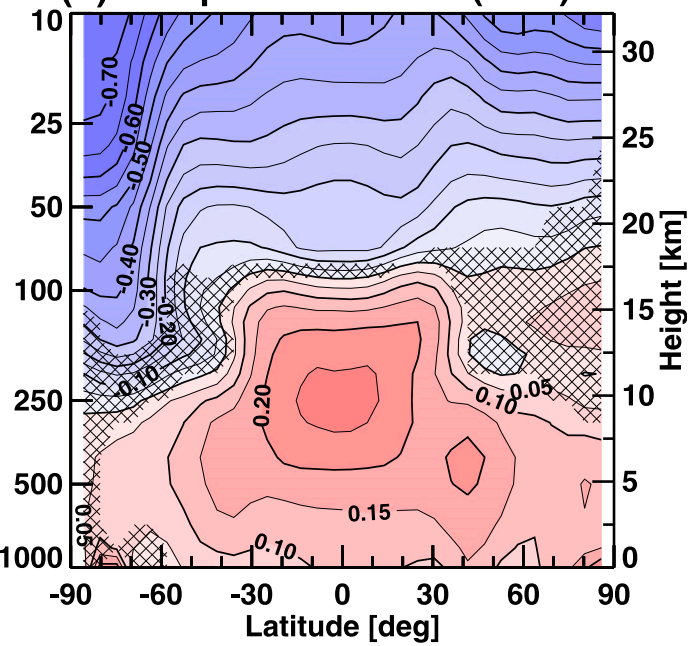

FIG. 4. Linear trends in annual mean temperature induced by (a) halocarbons and (b) $\mathrm{CO}_{2}\left(\mathrm{~K} \mathrm{decade}^{-1}\right)$. Cross hatching denotes regions where the trends are not significantly different from zero at the $95 \%$ level. Trends are computed from 1960 to 2010.

halocarbons, is also apparent in Fig. 4. The reason for the stronger cooling in the Antarctic stratosphere seen in Fig. $4 \mathrm{~b}$ is unclear, and may be related to the presence of the ozone hole. However, since this is outside of our region of interest we have not investigated its cause. Figures 3 and 4 demonstrate that the relative importance of halocarbons (with respect to $\mathrm{CO}_{2}$ ) is greatest in the tropical tropopause region where the warming extends a kilometer higher than the zero crossing of the $\mathrm{CO}_{2}$-induced temperature trend. This suggests that halocarbons play an important role in changes in the cold-point temperature (CPT). This is confirmed in Fig. 5a, which shows the CPT trends. While halocarbons and $\mathrm{CO}_{2}$ both increase the CPT, the halocarbon-induced trend is substantially larger than the $\mathrm{CO}_{2}$-induced trend and is statistically significant (see also Table 2).
We stress the finding that the halocarbon-induced temperature trends are weak in the lower stratospherea surprising result given the expected warming from the direct radiative effect of halocarbons (Fig. A1). Additional factors that offset the warming from halocarbons in the lower stratosphere are investigated below.

\section{b. Stratospheric water vapor and ozone}

Since the amount of water vapor entering the stratosphere is controlled by tropical lower stratosphere temperatures, changes in the latter will have an impact on the entry value of water vapor. This is confirmed in Fig. 5b, which shows trends in water vapor in the tropical lower stratosphere $(80 \mathrm{hPa})$, a height slightly above the cold-point tropopause $(90 \mathrm{hPa}$; Fig. 3). Both the (a) CP Temperature

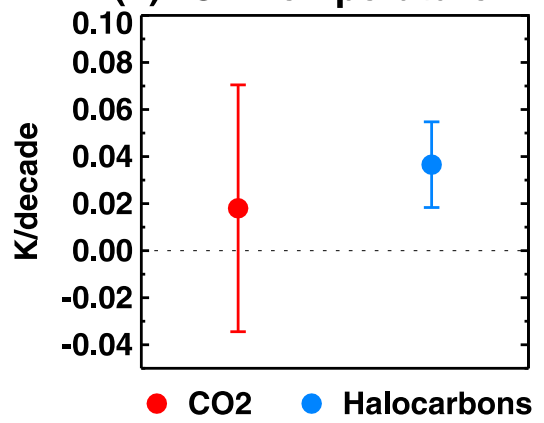

(b) Strat. Water Vapor

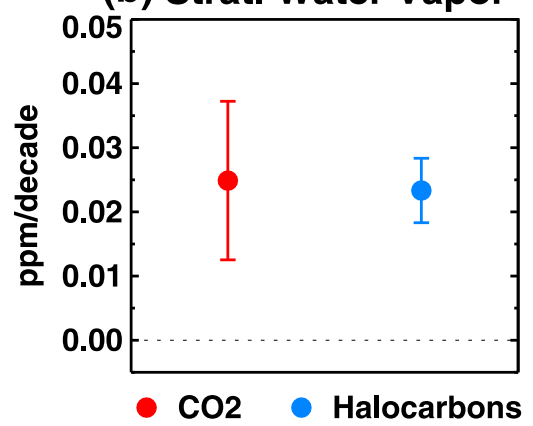

(c) Column Ozone

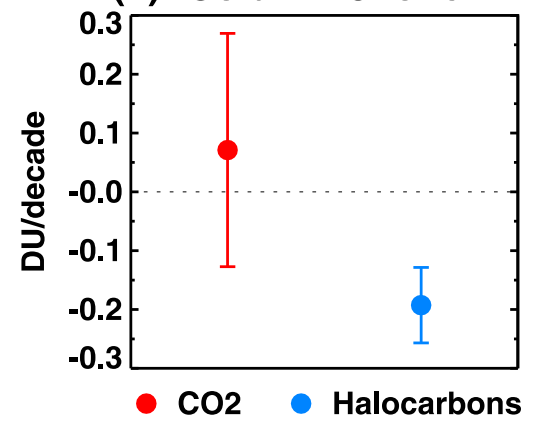

FIG. 5. Linear trends in annual mean tropical average (a) cold-point temperature, (b) 80-hPa water vapor, and (c) stratospheric column ozone (i.e., above $100 \mathrm{hPa}$ ), induced by halocarbons (blue) and $\mathrm{CO}_{2}$ (red). Error bars denote the $95 \%$ confidence levels. Tropical average is from $20^{\circ} \mathrm{S}$ to $20^{\circ} \mathrm{N}$. Trends are computed from 1960 to 2010. 
TABLE 2. Linear trends from 1960 to 2010 and $95 \%$ uncertainties in annual mean tropical-average, from top to bottom: 250 -hPa temperature $\left(\mathrm{K} \mathrm{decade}^{-1}\right)$, 50-hPa temperature $\left(\mathrm{K} \mathrm{decade}^{-1}\right)$, cold-point temperature $\left(\mathrm{K} \mathrm{decade}^{-1}\right)$, 80-hPa water vapor $\left(\mathrm{ppm} \mathrm{decade}^{-1}\right)$, stratospheric (above $100 \mathrm{hPa}$ ) column ozone (DU decade ${ }^{-1}$ ), 70-hPa residual vertical velocity $w^{*}\left(10^{-2} \mathrm{~mm} \mathrm{~s}^{-1}\right.$ decade $\left.^{-1}\right)$ due to the climate impacts of halocarbons and $\mathrm{CO}_{2}$, and the same but for $70-\mathrm{hPa}$ net upward mass $\left(10^{8} \mathrm{~kg} \mathrm{~s}^{-1} \mathrm{decade}^{-1}\right)$. Tropical average is from $20^{\circ} \mathrm{S}$ to $20^{\circ} \mathrm{N}$.

\begin{tabular}{lrr}
\hline \multicolumn{1}{c}{ Geophysical quantity } & \multicolumn{1}{c}{ Halocarbons } & \multicolumn{1}{c}{$\mathrm{CO}_{2}$} \\
\hline 250-hPa temperature & $0.111 \pm 0.016$ & $0.254 \pm 0.043$ \\
50-hPa temperature & $-0.022 \pm 0.023$ & $-0.167 \pm 0.073$ \\
Cold-point temperature & $0.037 \pm 0.018$ & $0.018 \pm 0.052$ \\
80-hPa water vapor & $0.023 \pm 0.005$ & $0.025 \pm 0.012$ \\
Stratospheric column ozone & $-0.193 \pm 0.064$ & $0.071 \pm 0.198$ \\
70-hPa $w^{*}$ & $0.152 \pm 0.059$ & $0.310 \pm 0.204$ \\
70-hPa net mass flux & $0.349 \pm 0.150$ & $0.343 \pm 0.408$ \\
\hline
\end{tabular}

halocarbon- and $\mathrm{CO}_{2}$-induced water vapor trends are positive and statistically significant; see also Table 2 . This moistening of the lower stratosphere is consistent with the increase of the CPT and the associated reduction in the freeze-drying of air as it passes from the troposphere to the stratosphere. Although the halocarboninduced moistening is comparable to that of $\mathrm{CO}_{2}$, while the halocarbon-induced CPT increases twice as much, the statistical uncertainties of the latter are considerable (such that a $\mathrm{CO}_{2}$-induced CPT increase of comparable magnitude to that from halocarbons cannot be excluded); moreover, we do not expect an exactly linear relationship between CPT and stratospheric water vapor for different kinds of forcings since stratospheric dehydration is controlled by the Lagrangian cold point (Fueglistaler et al. 2005), of which the annual zonal mean CPT is only a proxy.

The effects of halocarbons and $\mathrm{CO}_{2}$ on tropicalaverage ozone are shown in Figs. $5 \mathrm{c}$ and 6 . The trends in stratospheric column (i.e., above $100 \mathrm{hPa}$ ) ozone (Fig. 5c and Table 2) induced by the climate impacts of halocarbons and $\mathrm{CO}_{2}$ are of opposite sign, with halocarbons causing a statistically significant decrease in ozone and $\mathrm{CO}_{2}$ causing an increase. This sign difference can be understood by examining the ozone volume mixing ratio trend profiles (Fig. 6a). From 100 to $20 \mathrm{hPa}$ both the halocarbon- and $\mathrm{CO}_{2}$-induced trends are negative, with the $\mathrm{CO}_{2}$-induced trend being about twice as large as the halocarbon-induced trend. (The ozone trends at heights below $100 \mathrm{hPa}$ are nearly zero since the model does not have tropospheric chemistry.) As will be discussed shortly this lower stratospheric feature is due to increased tropical upwelling. In the upper stratosphere the ozone trend for $\mathrm{CO}_{2}$ is positive and much larger than it is for halocarbons as a result of the reduced photochemical destruction of ozone from the strong $\mathrm{CO}_{2}$ cooling (Barnett et al. 1975). Since the column is a mass-weighted integral, the positive trend in stratospheric column ozone for $\mathrm{CO}_{2}$ is due to the very large positive trend in upper stratospheric ozone. This is demonstrated in Fig. 6b, which shows the vertical integral of the tropical-average ozone trends shown in (a) Ozone VMR $20^{\circ} \mathrm{S}-20^{\circ} \mathrm{N}$

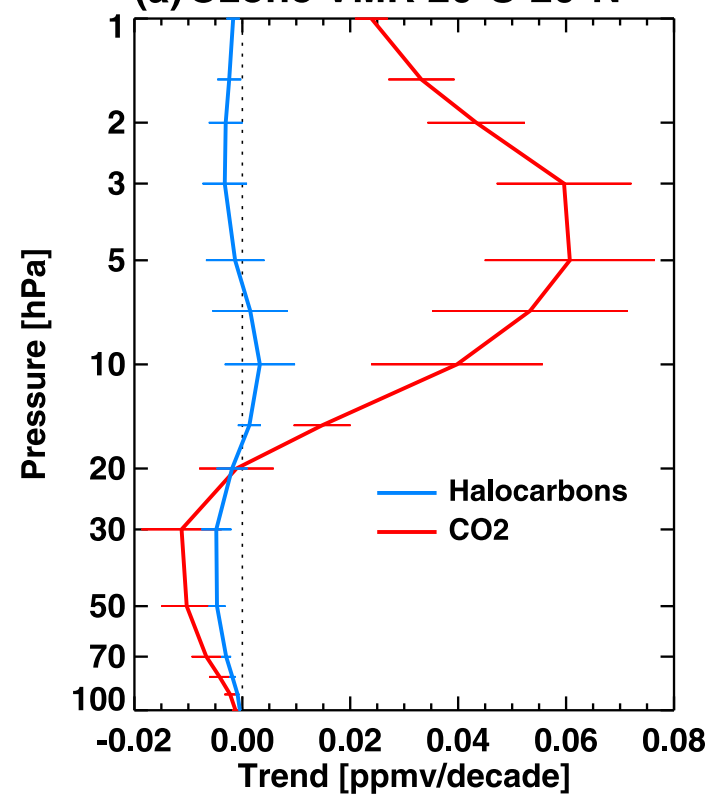

(b) Partial Column Ozone

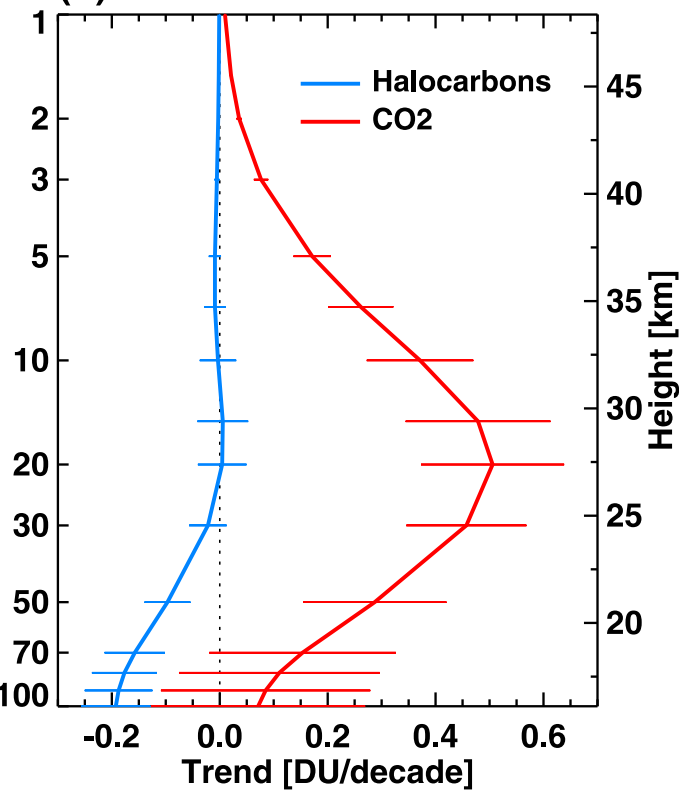

FIG. 6. (a) Linear trends in annual mean tropical average ozone volume mixing ratio induced by halocarbons (blue) and $\mathrm{CO}_{2}$ (red). (b) As in (a), but for partial column ozone from a given pressure up to $0.1 \mathrm{hPa}$. Error bars denote the $95 \%$ confidence levels. Tropical average is from $20^{\circ} \mathrm{S}$ to $20^{\circ} \mathrm{N}$. Trends are computed from 1960 to 2010. 


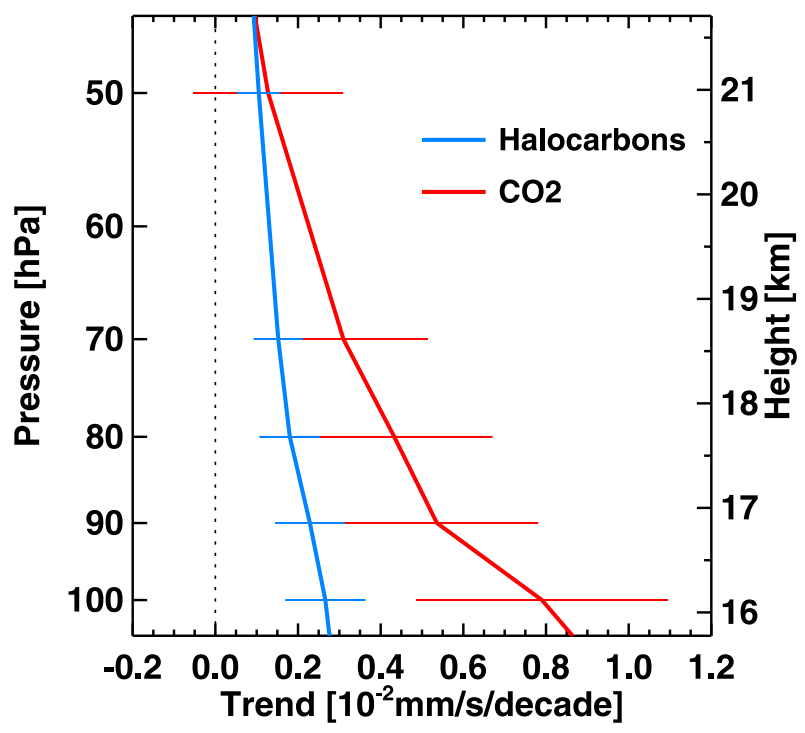

FIG. 7. As in Fig. 6a, but for residual vertical velocity.

Fig. 6a computed in Dobson units (DU) per decade. Note that by construction the vertical integral at $100 \mathrm{hPa}$ in Fig. $6 \mathrm{~b}$ is identical to the stratospheric column ozone trend in Fig. 5c. Since the halocarbon-induced trends in ozone are much smaller in the middle and upper stratosphere, the column-integrated trend is determined by the negative trends in lower stratospheric ozone (see Fig. 6b).

\section{c. Tropical upwelling}

Since chemical lifetimes of radiatively active gases in the lower stratosphere are much longer than transport time scales, lower stratospheric ozone is under dynamical control. Consequently, the negative trends in ozone seen in Fig. 6a at heights below $20 \mathrm{hPa}$ reflect increased tropical upwelling, which draws ozone-poor air from the troposphere into the stratosphere. This is confirmed in Fig. 7, which shows vertical profiles of the trends in the tropical-average residual vertical velocity $w^{*}$; see also Table 2. The trends are positive for both halocarbons and $\mathrm{CO}_{2}$, with the latter being a little over a factor of 2 stronger, which is consistent with the larger ozone trends between 100 and $20 \mathrm{hPa}$ for $\mathrm{CO}_{2}$ (Fig. 6a). Increased tropical upwelling in the lower stratosphere is an expected result of tropospheric warming together with an elevated tropical tropopause, which leads to strengthened winds on the upper flank of the subtropical jets and thus to increased wave drag in this region through an upward shift both in Rossby wave critical levels (Shepherd and McLandress 2011) and in breaking levels of parameterized orographic gravity waves ( $\mathrm{Li}$ et al. 2008; McLandress and Shepherd 2009).

Figure 8 shows trends in the net upward mass flux at $70 \mathrm{hPa}$ (see also Table 2), which is the commonly used

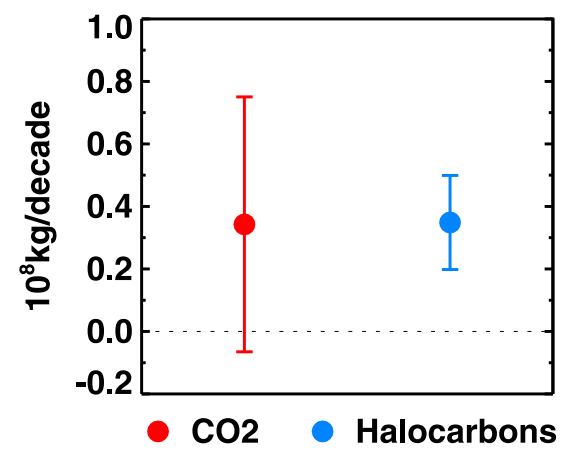

FIG. 8. Linear trends in annual mean net upward mass flux at $70 \mathrm{hPa}$ induced by halocarbons (blue) and $\mathrm{CO}_{2}$ (red). Error bars denote the $95 \%$ confidence levels. Trends are computed from 1960 to 2010 .

metric for defining the Brewer-Dobson circulation (e.g., Butchart et al. 2010), and is computed by averaging $w^{*}$ over the latitudes where there is upwelling as described in McLandress and Shepherd (2009). Not surprisingly (given Fig. 7), the mass flux trends are positive for both the halocarbon- and $\mathrm{CO}_{2}$-induced changes. What is surprising, however, is that the trend induced by halocarbons is as large as that for $\mathrm{CO}_{2}$, in spite of the fact that the tropical-average $\left(20^{\circ} \mathrm{S}-20^{\circ} \mathrm{N}\right)$ trend in $w^{*}$ is only half as large. This is attributed to larger positive halocarboninduced trends in $w^{*}$ between $20^{\circ}$ and the "turnaround" latitudes where $w^{*}$ changes sign, suggesting differences in the changes in subtropical wave driving, which is however beyond the scope of this paper.

The increase in tropical lower stratosphere upwelling induced by the halocarbon and $\mathrm{CO}_{2}$ increases is of course compensated for by an increase in extratropical downwelling. This is reflected in the latitudinal variation of the column ozone trends shown in Fig. 9. For

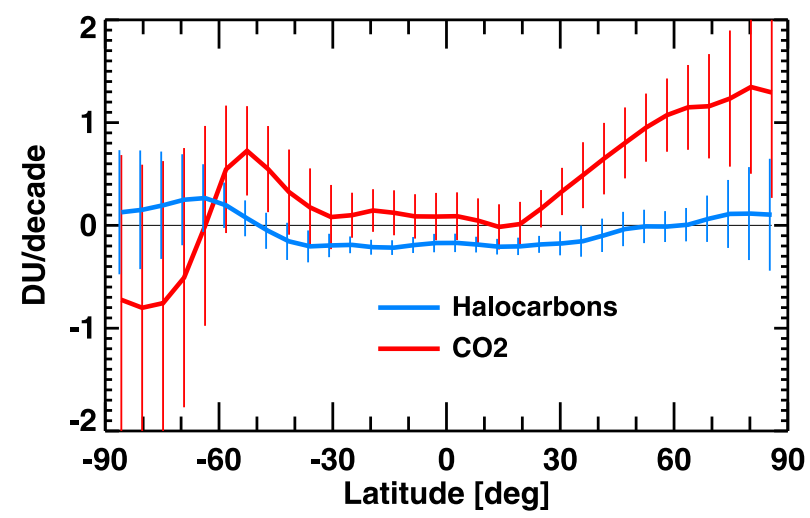

FIG. 9. Linear trends in annual mean stratospheric column ozone (i.e., above $100 \mathrm{hPa}$ ) vs latitude induced by halocarbons (blue) and $\mathrm{CO}_{2}$ (red). Error bars denote the $95 \%$ confidence levels; error bars are not extended beyond the vertical range of the plot. Trends are computed from 1960 to 2010. 
(a) Net (Halocarbon Effect)

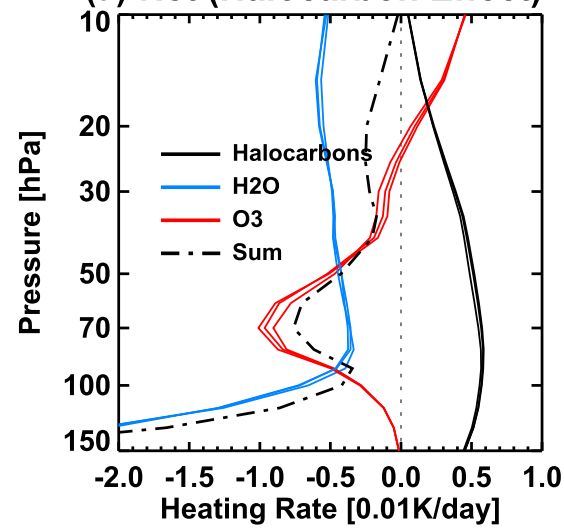

(d) Net (CO2 Effect)

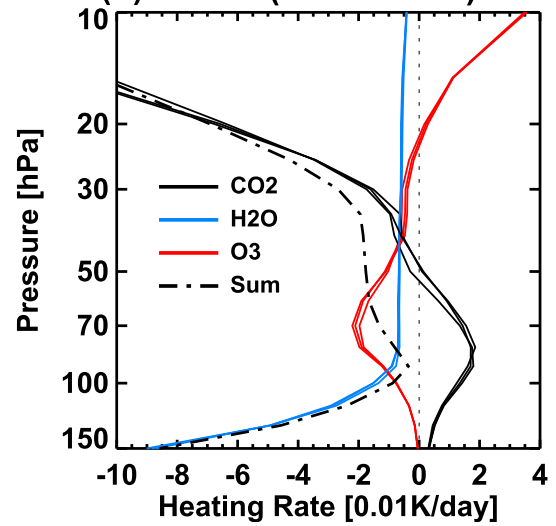

(b) LW (Halocarbon Effect)

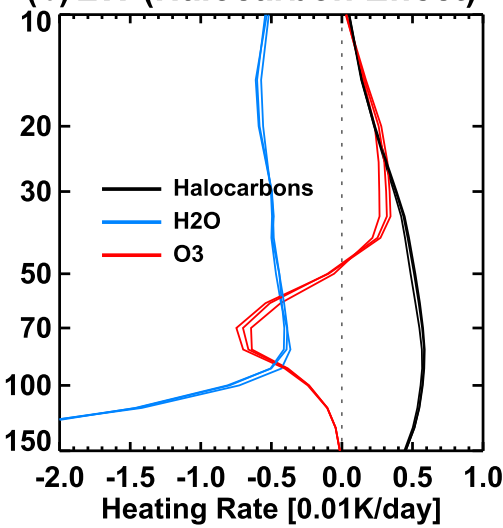

(e) LW (CO2 Effect)

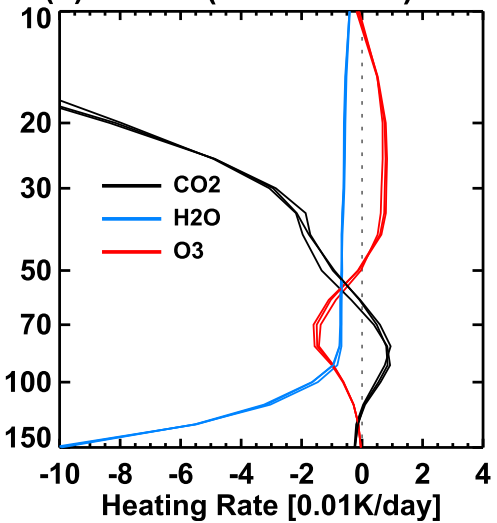

(c) SW (Halocarbon Effect)

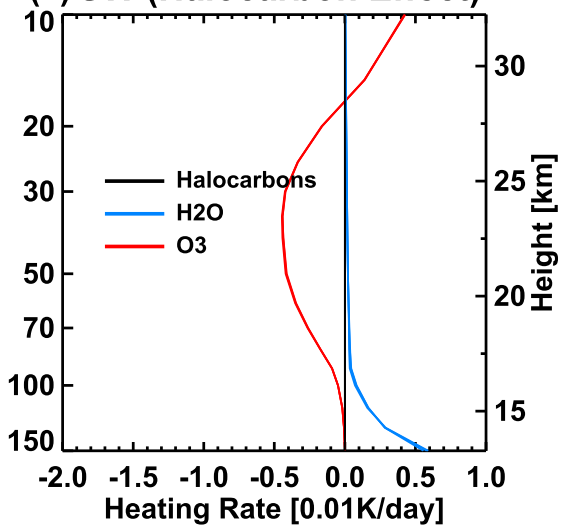

(f) SW (CO2 Effect)

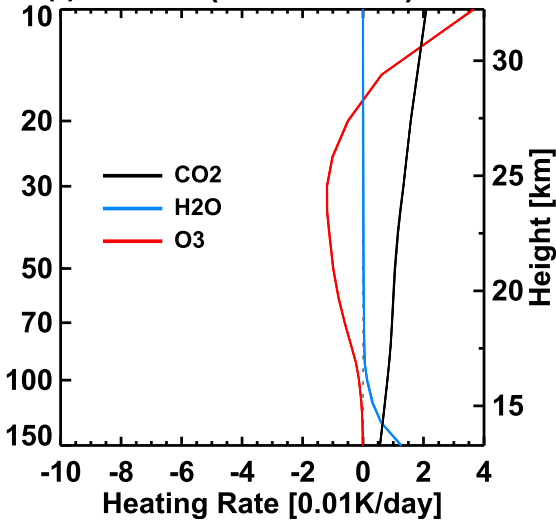

FIG. 10. Direct and indirect tropical-average radiative heating rates due to changes in (top) halocarbons and (bottom) $\mathrm{CO}_{2}$ computed using the offline RT code discussed in appendix B: (a),(d) net (i.e., longwave plus shortwave), (b),(e) longwave, and (c),(f) shortwave. The solid black curves denote the direct effects due to changes in either halocarbons or $\mathrm{CO}_{2}$. The colored curves denote the indirect effects due to changes in water vapor (blue) and ozone (red) that are induced by the changes in halocarbons and $\mathrm{CO}_{2}$. The sum of the direct and indirect net heating terms is given by the dashed black curves in the left-hand panels. Results are averaged from $20^{\circ} \mathrm{S}$ to $20^{\circ} \mathrm{N}$.

halocarbons the ozone increase in the extratropics and decrease in the tropics is a direct consequence of the strengthening of the Brewer-Dobson circulation, with a small global-mean trend of $-0.11 \pm 0.04$ DU decade ${ }^{-1}$. For $\mathrm{CO}_{2}$ the picture is more complicated, with a globalmean trend of $0.30 \pm 0.09 \mathrm{DU}_{\text {decade }}{ }^{-1}$ due to upper stratospheric cooling, which is modulated by the strengthened Brewer-Dobson circulation. This leads to a very large increase in column ozone in the northern extratropics and to a much smaller increase in the tropics. The large negative $\mathrm{CO}_{2}$-induced trends in the Antarctic are due to changes in springtime circulation, but are not statistically robust as the uncertainty interval encompasses zero.

\section{d. Direct and indirect radiative effects}

The radiative contribution to the halocarbon- and $\mathrm{CO}_{2}-$ induced temperature trends in the tropical UTLS shown in Figs. 3 and 4 includes not only the direct radiative response to the changes in concentrations of those gases, but also an indirect radiative response to the changes in water vapor and ozone shown in Figs. 5 and 6. To help separate these two effects we perform offline radiative transfer (RT) calculations using, as a reference state, initial conditions from CMAM for 1 January. Since the seasonal variations in temperature and constituents are not large in the tropical lower stratosphere, the use of the January reference state is not seen as problematic. The RT calculations enable us to quantify the radiative impact of each of the different gases in the absence of feedbacks. Details concerning the offline RT calculations are discussed in appendix B.

Figure 10 shows the direct and indirect contributions to the radiative heating due to changes in halocarbons (top) and $\mathrm{CO}_{2}$ (bottom) computed using the offline RT code. Note the change in scale between the top and bottom rows. The radiative heating is split into the $\mathrm{LW}$ (middle) and shortwave (SW; right) components and the respective sum (net; left). Note that for the halocarbons the radiative heating is only in the LW component. The three sets of colored curves in each panel each consist of 
three members, one for each of the three reference states. The differences between the individual members are minimal, indicating that the heating rate changes are robust to realistic changes in the reference state.

Starting with the direct radiative effect (black solid curves in Fig. 10) we see that halocarbons cause net warming up to $10 \mathrm{hPa}$ (Fig. 10a), which is due entirely to LW radiation (Fig. 10b). This is consistent with Fig. A1. For $\mathrm{CO}_{2}$ there are changes in both $\mathrm{LW}$ and $\mathrm{SW}$ heating. Above about $70 \mathrm{hPa}$ the LW cooling by $\mathrm{CO}_{2}$ has increased (Fig. 10e) as a result of the $\mathrm{CO}_{2}$ increase. Near the cold-point tropopause $(90 \mathrm{hPa})$ the $\mathrm{CO}_{2}$ increase instead causes enhanced LW warming, as a result of the convergence of radiative fluxes in this cold region of the atmosphere (e.g., Clough and Iacono 1995). $\mathrm{CO}_{2}$ also absorbs solar radiation in the near infrared (e.g., Fomichev et al. 2004), which explains the increase in SW heating by $\mathrm{CO}_{2}$ in Fig. 10f. This increase in SW heating enhances the LW warming near the tropopause, resulting in a deeper vertical region of net warming (Fig. 10d).

The indirect radiative effects are given by the colored curves in Fig. 10. Here changes in both the LW and SW occur. For both halocarbons (Fig. 10a) and $\mathrm{CO}_{2}$ (Fig. 10d), the decreased ozone from strengthened tropical upwelling and the increased water vapor from a higher CPT both result in net cooling in the height region below $20 \mathrm{hPa}$. This cooling is strong enough to offset the direct radiative warming, resulting in the sum of the direct and indirect terms (black dashed) being negative throughout the plotted domain. In particular, this explains the negative temperature trends in the tropical stratosphere due to halocarbons (Figs. 3 and 4a). Of the two gases, the net cooling by ozone (red curves in Figs. 10a and 10d) is stronger by about a factor of 2 than the cooling by water vapor (blue) in the lower stratosphere, but in the case of the halocarbon-induced changes, the cooling by water vapor is sufficient to offset the direct radiative warming from halocarbons in the height region above about $40 \mathrm{hPa}$. Note that in the vicinity of the cold-point tropopause (and further below), the overall warming seen in earlier figures results from the increased SSTs, which are not included in these purely radiative calculations.

These results show that in the tropical UTLS, the indirect radiative cooling from increasing water vapor and decreasing ozone, which both result from dynamical feedbacks, is of roughly comparable magnitude to the direct radiative warming from halocarbons or $\mathrm{CO}_{2}$, emphasizing the complexity of the radiative-dynamical balance in this region. For the halocarbon-induced changes, the indirect radiative cooling is sufficient to explain the lack of a tropical warming (in fact a weak tropical cooling) in the full temperature response at altitudes above about $80 \mathrm{hPa}$. For the $\mathrm{CO}_{2}$-induced changes, the indirect radiative cooling lowers the altitude at which cooling is found in the full temperature response.

\section{Conclusions and discussion}

A version of the Canadian Middle Atmosphere Model that is coupled to a dynamic ocean model is used to compare the climate impact of past changes (1960-2010) in halocarbons and $\mathrm{CO}_{2}$ in the tropical UTLS region. Since the model has interactive stratospheric chemistry, the radiative, chemical, and dynamical feedbacks induced by the changes in halocarbons and $\mathrm{CO}_{2}$, which need to be considered for a proper assessment of the climate impacts, are fully simulated. By differencing pairs of simulations in which the concentrations of the halocarbons and $\mathrm{CO}_{2}$ evolve transiently with simulations in which they are held fixed in the radiation code, their climate impact is isolated. Our study is the first of its kind to quantify the climate impact of halocarbons on tropospheric temperatures using a coupled model. Our study is also the first to examine the climate impacts of the halocarbon changes on the stratosphere, although there have been numerous studies examining the chemical impact of past changes of CFCs on stratospheric temperatures resulting from ozone loss.

It would be remiss of us not to remind the reader that the simulations we used contained an error in the LW radiation code that resulted in an overestimation of the halocarbon heating rates. We corrected this error by scaling the halocarbon-induced trends by a factor of 0.4 , which is the ratio of the corrected and uncorrected halocarbon heating rates. While this linear scaling is entirely valid for the heating rates (since the halocarbons are optically thin), as is verified in Fig. A1a, it is less obvious for the response to the heating. However, as discussed in section $2 b$, the heating rate perturbations are small; moreover, since we are scaling down the response, the range of halocarbon heating rates represented by the scaling is already present in the simulations, and we see no evidence of nonlinearity (within the large amount of natural variability) in the simulations. We therefore believe there are prima facie grounds for accepting the linear scaling. In any case, precise linearity is not critical to our conclusions: since we are examining differences in pairs of simulations that differ only in their halocarbon concentrations, the differences we identify are unequivocally due to halocarbons.

The past changes in halocarbons are shown to warm the upper troposphere, with the warming at $250 \mathrm{hPa}$ being $\sim 40 \%$ of that due to $\mathrm{CO}_{2}$. The halocarboninduced increase in the cold-point temperature is about twice as large as for $\mathrm{CO}_{2}$. In the tropical lower stratosphere (LS), the halocarbon-induced temperature trends are weakly negative, in spite of the fact that the 
direct LW heating from halocarbons is positive. This indicates that estimates of the direct radiative effect from halocarbons (e.g., Forster and Joshi 2005) are missing very important feedbacks.

In conjunction with the increase in cold-point temperature, tropical LS water vapor trends induced by the halocarbon changes are positive and as large as those induced by the $\mathrm{CO}_{2}$ changes. This moistening of the LS is a result of reduced freeze-drying of air as it passes from the troposphere into the stratosphere.

The climate impact of past changes in halocarbons and $\mathrm{CO}_{2}$ also produces changes in tropical stratospheric ozone, which vary in sign depending upon the altitude range. In the $\mathrm{LS}$ the halocarbon- and $\mathrm{CO}_{2}$-induced ozone trends are both negative. This is a result of the climatechange induced increase in tropical LS upwelling, which transports ozone-poor air upward from the troposphere. The LS ozone trends for halocarbons are about half as large as the trends for $\mathrm{CO}_{2}$, consistent with the finding that the tropical LS upwelling trends induced by the halocarbons are half as large as the trends induced by $\mathrm{CO}_{2}$. In the upper stratosphere, ozone trends associated with the radiative effects of halocarbons are small and are dwarfed by the large positive trends induced by the $\mathrm{CO}_{2}$ increases, with the latter being a consequence of the reduced photochemical destruction of ozone. As a result, the changes in tropical stratospheric column (i.e., heights above $100 \mathrm{hPa}$ ) ozone are opposite in sign, negative for halocarbons and positive for $\mathrm{CO}_{2}$.

The negative tropical LS ozone trends induced by halocarbons indicate that the decrease in tropical LS ozone seen in observations (Randel and Wu 2007) is likely partly attributable to the climate impact of halocarbons, and should not be expected to continue as strongly in the future, whereas the $\mathrm{CO}_{2}$-induced tropical LS ozone decrease is offset in the column by the upper stratospheric increase. The decrease in tropical stratospheric column ozone that is simulated by CCMs in response to increasing concentrations of GHGs (SPARC CCMVal 2010) is assumed to be a result of increased upwelling (WMO 2011). Our results indicate that, in the case of $\mathrm{CO}_{2}$, the ozone increase in the upper stratosphere due to $\mathrm{CO}_{2}$-induced cooling outweighs the ozone decrease in the LS due to increased upwelling. This indicates that the net effect of climate change on future changes in tropical stratospheric column ozone will depend on the mix of GHGs in the scenario. This may explain why the behavior of tropical column ozone is not monotonic in time in the CCMVal2 models (see Fig. 9.2 of SPARC CCMVal 2010), since in those simulations the replacement halocarbons (hydrofluorocarbons and perfluorcarbons) are projected to increase strongly in the second half of the twenty-first century.
To assess the radiative feedbacks induced by changes in stratospheric ozone and water vapor (i.e., the indirect radiative effects), we perform offline RT calculations to isolate the effects of changes in the individual gases on radiative heating. These calculations are used to help understand why there is no halocarbon-induced warming in the tropical stratosphere, despite the fact that the direct radiative effect of an increase in halocarbons is warming. Our calculations show that the halocarbon-induced increase in stratospheric water vapor and decrease in LS ozone both result in an indirect radiative cooling that, in conjunction with the adiabatic cooling from increased upwelling, outweighs the direct warming by halocarbons, thus explaining the net halocarbon-induced cooling in the LS. Of the two gases, the indirect radiative effect of ozone is about a factor of 2 larger than that of water vapor in the vicinity of the cold-point tropopause, while water vapor dominates at heights above $50 \mathrm{hPa}$.

For $\mathrm{CO}_{2}$ the indirect cooling from increased water vapor and decreased ozone is of comparable magnitude to the direct warming from $\mathrm{CO}_{2}$ in the vicinity of the cold-point tropopause, and (together with the increased tropical LS upwelling) is sufficient to lower the altitude at which $\mathrm{CO}_{2}$ increases induce tropical stratospheric cooling from about $50 \mathrm{hPa}$ (as would be expected on radiative grounds alone) to $90 \mathrm{hPa}$, thereby also explaining the relatively weak increase in cold-point temperature due to $\mathrm{CO}_{2}$ increases.

We are confident that the water vapor radiative feedback discussed here is a robust result that should be operative in models containing the necessary physics (see, e.g., Stuber et al. 2001). The robustness stems from the simplicity of the feedback mechanism, namely the moistening of the stratosphere due to GHG-induced warming of the tropopause and the ensuing increase in LW cooling in the LS from the increased water vapor.

The importance found here of the ozone-induced cooling in the lowest part of the tropical stratosphere is consistent with the findings of two recent modeling studies. Polvani and Solomon (2012) show that the tropical LS cooling over the last half of the twentieth century is mainly due to the observed ozone decrease, and not to other effects of changes in GHGs or SSTs. Our results are not directly comparable with theirs because of the different experimental setup. However, since the observed tropical LS ozone decrease is understood to be mainly the result of the GHG-induced upwelling and not chemical ozone depletion (Plummer et al. 2010; WMO 2011), the ozone-induced LS cooling identified by Polvani and Solomon (2012) can be interpreted here as the indirect ozone radiative feedback from GHG increases. Dietmüller et al. (2014) quantify the effect of interactive ozone on the climate response to increased $\mathrm{CO}_{2}$. They show that the ozone-induced tropical lower stratosphere cooling reduces the $\mathrm{CO}_{2}$-induced 

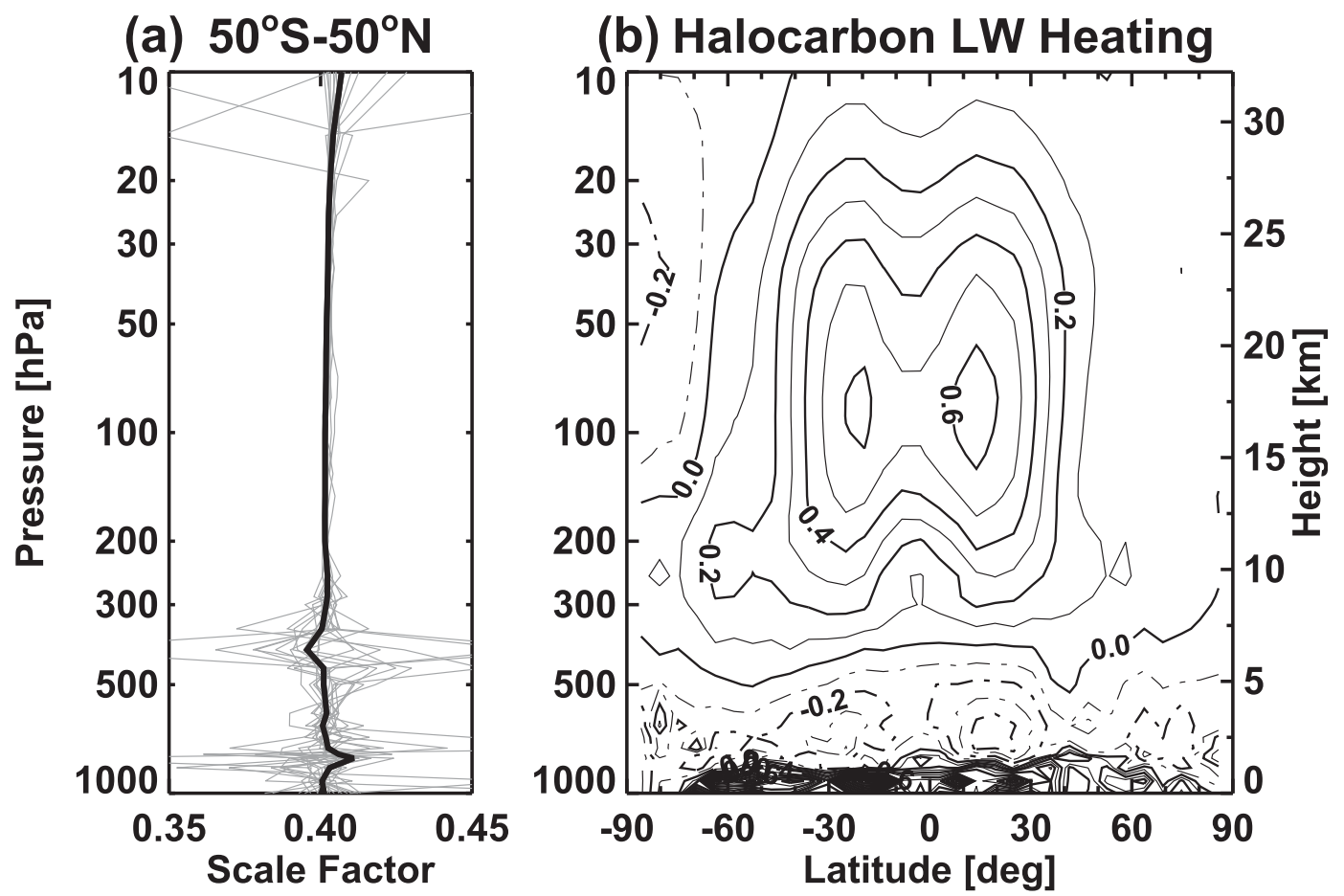

FIG. A1. (a) Ratio of the halocarbon longwave heating rate for the corrected and uncorrected longwave absorption cross sections computing using the offline RT code discussed in appendix B. The thick black line is the average from $50^{\circ} \mathrm{S}$ to $50^{\circ} \mathrm{N}$; the thin gray lines are the zonal-mean ratios at the individual latitudes in this range. The ratio is very nearly equal to 0.4 , which is the value used to correct the halocarbon-induced trends. (b) Halocarbon heating rate $\left(0.01 \mathrm{~K} \mathrm{day}^{-1}\right)$ computed $^{-}$ using the corrected absorption cross section. Initial conditions are for 1 Jan 2001 of the GHG simulation.

stratospheric water vapor increase from what it would otherwise be, and that this is the main reason for interactive ozone reducing the climate sensitivity parameter (by $3.4 \%$ for doubled $\mathrm{CO}_{2}$ and by $8.4 \%$ for quadrupled $\mathrm{CO}_{2}$ ).

These results show the disproportionately large climate impact of halocarbons on the tropical UTLS region, compared to their surface radiative forcing, which means that the evolution of this region will not simply scale with surface warming but will depend on the mix of GHGs in the scenario. Perhaps more significantly, the results also show the importance of both water vapor and ozone feedbacks in determining the response of the tropical UTLS region to radiative forcing from greenhouse gases in general. Therefore, it is necessary to represent the reductions in lower stratospheric ozone resulting from increases in tropical upwelling in order to correctly capture the climate response in this region.

Acknowledgments. The authors thank Jason Cole for his comments on an earlier version of the manuscript. A significant part of this work was made possible through funding by the Canadian Foundation for Climate and Atmospheric Sciences through the C-SPARC project, with additional institutional support from the Canadian Centre for Climate Modelling and Analysis, who provided the model code and supercomputing time. Additional support was provided by a Grant and Contribution from Environment Canada to the University of Toronto.

\section{APPENDIX A}

\section{Scaling Factor for Halocarbon LW Heating Rates}

Herein is the demonstration that a constant scale factor of 0.4 can be used to correct the halocarbon LW heating rates used in these simulations. Since halocarbons at the concentrations assumed here are optically thin, the associated heating rates will be very nearly linearly proportional to the absorption cross sections. Consequently, a single multiplicative factor can be applied to scale down the heating rates to their correct values (i.e., the values obtained when the correct absorption cross section is used). To demonstrate this we perform offline radiative transfer (RT) calculations using initial conditions from a single member of the GHG simulation (see appendix B for more details). The halocarbon heating rate is obtained by differencing the total LW heating from runs with and without halocarbons. The results of these experiments are presented in Fig. A1. The thick black curve in the left panel shows the 
vertical profile of the ratio of the halocarbon heating rates computed using the correct and incorrect absorption coefficients and averaged between $50^{\circ} \mathrm{S}$ and $50^{\circ} \mathrm{N}$. Except where the heating rate is zero (and the ratio is infinite; see Fig. A1b), the ratio is very nearly equal to 0.4 , as stated above. The thin gray curves are vertical profiles of the zonal-mean ratios at the individual latitudes between $50^{\circ} \mathrm{S}$ and $50^{\circ} \mathrm{N}$. With the exception of the heights where the halocarbon heating is zero, the ratios are nearly identical to the latitudinal average, indicating that there is no latitudinal variation in the scale factor. The scale factor is also independent of time, as verified by offline RT calculations using initial conditions from other years spread across the 50-yr period (not shown). The value of the scale factor is also in close agreement with radiative forcing calculations using the radiative transfer code from CGCM3 on which CMAM is based (J. Li 2013, personal communication).

Figure A1b shows the corrected zonal-mean LW heating rate due to halocarbons computed using the offline RT code for 1 January 2001 . The heating rate maximizes in the tropical upper troposphere (near $100 \mathrm{hPa}$ ), where the air temperatures are lowest. The cooling in the lower troposphere occurs because the temperature difference with the surface is not large enough for the net effect of absorption of upwelling LW radiation from the surface to exceed the atmospheric emission. From the middle troposphere to the top of the plotted domain at $10 \mathrm{hPa}$ halocarbons warm the atmosphere. This is in contrast to $\mathrm{CO}_{2}$, which cools the stratosphere.

\section{APPENDIX B}

\section{Offline Radiative Transfer Calculations}

Since an offline version of the radiative transfer (RT) code used in this version of CMAM was not available, we used CMAM to perform these calculations. This was done by integrating the model forward in time for a single time step, which ensures that there are no feedbacks due to changes in temperature, clouds, or other radiatively active gases. For simplicity, we refer to this in the text as the offline RT code. The radiative heating rates thus produced are instantaneous, and we do not attempt to infer adjusted temperatures, as Newtonian cooling has been shown to be a very poor approximation to LW cooling in the tropical lower stratosphere (Hitchcock et al. 2010) since the exchange terms in the RT equation are important.

The radiative impact of individual gases is obtained by differencing the heating rates computed from a reference state with those for a perturbed state in which the concentrations of a particular gas (halocarbons, $\mathrm{CO}_{2}$, water vapor, or ozone) are changed. For the RT calculations discussed in section $3 \mathrm{~d}$ the reference state is chosen from the REF-B2 simulation for present-day conditions, namely year 2010. Since the initial conditions needed to restart the model were archived only at the end of each year, offline RT calculations can only be performed for 1 January. However, since our focus is on the tropics where the annual cycle is weak, January results are expected to be representative of the annual mean. To assess the sensitivity of the results to the initial conditions we use three different reference states, all for the same year (2010), but for the three ensemble members of the REF-B2 simulation.

The perturbed states are constructed by changing the concentration of one gas at a time. The perturbation that is applied is the change in concentration of that gas from 2010 to 1960 . For the direct radiative effect, it is simply the change in the prescribed spatially uniform value of either halocarbons or $\mathrm{CO}_{2}$ as given by their time series shown in Fig. 1. For the indirect radiative effect, the procedure is more involved. In this case the perturbation is constructed from the halocarbon- or $\mathrm{CO}_{2}$-induced trends in water vapor or ozone discussed in section $3 \mathrm{~b}$. The trends are first converted to an absolute amount by multiplying by 5 decades. The resulting perturbation, which is a function of latitude and pressure, is then interpolated onto the model grid and subtracted from the corresponding field of the reference state. The calculation produces heating rates at all longitudes (and latitudes), which are then zonally averaged. The zonal average at a fixed absolute time ensures that the short wave component of the heating samples the full diurnal range of solar zenith angles.

\section{REFERENCES}

Barnett, J. J., J. T. Houghton, and J. A. Pyle, 1975: The temperature dependence of the ozone concentration near the stratosphere. Quart. J. Roy. Meteor. Soc., 101, 245-257, doi:10.1002/ qj. 49710142808 .

Butchart, N., and Coauthors, 2010: Chemistry-climate model simulations of twenty-first century stratospheric climate and circulation changes. J. Climate, 23, 5349-5374, doi:10.1175/ 2010JCLI3404.1.

Clough, S. A., and M. J. Iacono, 1995: Line-by-line calculation of atmospheric fluxes and cooling rates. 2. Application to carbondioxide, ozone, methane, nitrous oxide and the halocarbons. J. Geophys. Res., 100, 16519-16535, doi:10.1029/95JD01386.

Collins, W. D., and Coauthors, 2006: Radiative forcing by wellmixed greenhouse gases: Estimates from climate models in the Intergovernmental Panel on Climate Change (IPCC) Fourth Assessment Report (AR4). J. Geophys. Res., 111, D14317, doi:10.1029/2005JD006713.

Dickinson, R. E., S. C. Liu, and T. M. Donahue, 1978: Effect of chlorofluoromethane infrared radiation on zonal atmospheric temperatures. J. Atmos. Sci., 35, 2142-2152, doi:10.1175/ 1520-0469(1978)035<2142:EOCIRO>2.0.CO;2. 
Dietmüller, S., M. Ponater, and R. Sausen, 2014: Interactive ozone induces a negative feedback in $\mathrm{CO}_{2}$-driven climate change simulations. J. Geophys. Res. Atmos., 119, 1796-1805, doi:10.1002/2013JD020575.

Eyring, V., and Coauthors, 2008: Overview of the new CCMVal reference and sensitivity simulations in support of upcoming ozone and climate assessments and the planned SPARC CCMVal Report. SPARC Newsletter, SPARC Office, Toronto, Ontario, Canada, Vol. 30, 20-26. [Available online at http://www.atmosp.physics.utoronto.ca/SPARC/Newsletter30Web/ Overciew_CCMVal.html.]

Fomichev, V. I., C. Fu, J. de Grandpré, S. R. Beagley, V. P. Ogibalov, and J. C. McConnell, 2004: Model thermal response to minor radiative energy sources and sinks in the middle atmosphere. J. Geophys. Res., 109, D19107, doi:10.1029/2004JD004892.

Forster, P., and M. Joshi, 2005: The role of halocarbons in the climate change of the troposphere and stratosphere. Climatic Change, 71, 249-266, doi:10.1007/s10584-005-5955-7.

radiative forcing. Climate Dyn., 13, 547-560, doi:10.1007/ s003820050182.

Freckleton, R. S., E. J. Highwood, K. P. Shine, O. Wild, K. S. Law, and M. G. Sanderson, 1998: Greenhouse gas radiative forcing: Effects of averaging and inhomogeneities in trace gas distribution. Quart. J. Roy. Meteor. Soc., 124, 2099-2127, doi:10.1002/qj.49712455014.

Fueglistaler, S., M. Bonazzola, P. H. Haynes, and T. Peter, 2005: Stratospheric water vapor predicted from the Lagrangian temperature history of air entering the stratosphere in the tropics. J. Geophys. Res., 110, D08107, doi:10.1029/ 2004JD005516.

Gettelman, A., and Coauthors, 2010: Multimodel assessment of the upper troposphere and lower stratosphere: Tropics and global trends. J. Geophys. Res., 115, D00M08, doi:10.1029/ 2009JD013638.

Hitchcock, P., T. G. Shepherd, and S. Yoden, 2010: On the approximation of local and linear radiative damping in the middle atmosphere. J. Atmos. Sci., 67, 2070-2085, doi:10.1175/ 2009JAS3286.1.

Houghton, J. T., Y. Ding, D. J. Griggs, M. Noguer, P. J. van der Linden, X. Dai, K. Maskell, and C. A. Johnson, Eds., 2001: Climate Change 2001: The Scientific Basis. Cambridge University Press, $881 \mathrm{pp}$.

Kellmann, S., and Coauthors, 2012: Global CFC-11 $\left(\mathrm{CCl}_{3} \mathrm{~F}\right)$ and CFC-12 $\left(\mathrm{CCl}_{2} \mathrm{~F}_{2}\right)$ measurements with the Michelson Interferometer for Passive Atmospheric Sounding (MIPAS): Retrieval, climatologies and trends. Atmos. Chem. Phys., 12, 11 857-11 875, doi:10.5194/acp-12-11857-2012.

Li, F., J. Austin, and J. Wilson, 2008: The strength of the BrewerDobson circulation in a changing climate: Coupled chemistryclimate model simulations. J. Climate, 21, 40-57, doi:10.1175/ 2007JCLI1663.1.

McLandress, C., and T. G. Shepherd, 2009: Simulated anthropogenic changes in the Brewer-Dobson circulation, including its extension to high latitudes. J. Climate, 22, 1516-1540, doi:10.1175/2008JCLI2679.1.

, A. I. Jonsson, D. A. Plummer, M. C. Reader, J. F. Scinocca, and T. G. Shepherd, 2010: Separating the dynamical effects of climate change and ozone depletion. Part I: Southern
Hemisphere stratosphere. J. Climate, 23, 5002-5020, doi:10.1175/ 2010JCLI3586.1.

Morcrette, J.-J., 1991: Radiation and cloud radiative properties in the ECMWF operational weather forecast model. J. Geophys. Res., 96, 9121-9132, doi:10.1029/89JD01597.

Myhre, G., and F. Stordal, 1997: Role of spatial and temporal variations in the computation of radiative forcing and GWP. J. Geophys. Res., 102, 11 181-11200, doi:10.1029/97JD00148.

Plummer, D. A., J. F. Scinocca, T. G. Shepherd, M. C. Reader, and A. I. Jonsson, 2010: Contributions to stratospheric change from ozone depleting substances and greenhouse gases. Atmos. Chem. Phys., 10, 9647-9694, doi:10.5194/acpd-10-9647-2010.

Polvani, L. M., and S. Solomon, 2012: The signature of ozone depletion on tropical temperature trends, as revealed by their seasonal cycle in model integrations with single forcings. J. Geophys. Res., 117, D17102, doi:10.1029/2012JD017719.

Ramanathan, V., 1975: Greenhouse effect due to chlorofluorocarbons: Climatic implications. Science, 190, 50-52, doi:10.1126/science.190.4209.50.

_ - and Coauthors, 1987: Climate-chemical interactions and effects of changing atmospheric trace gases. Rev. Geophys., 25, 1441-1482, doi:10.1029/RG025i007p01441.

Randel, W. J., and F. Wu, 2007: A stratospheric ozone profile data set for 1979-2005: Variability, trends, and comparisons with column ozone data. J. Geophys. Res., 112, D06313, doi:10.1029/2006JD007339.

Scinocca, J. F., N. A. McFarlane, M. Lazare, J. Li, and D. Plummer, 2008: The CCCma third generation AGCM and its extension into the middle atmosphere. Atmos. Chem. Phys., 8, 70557074, doi:10.5194/acp-8-7055-2008.

Shepherd, T. G., and C. McLandress, 2011: A robust mechanism for strengthening of the Brewer-Dobson circulation in response to climate change: Critical-layer control of subtropical wave breaking. J. Atmos. Sci., 68, 784-797, doi:10.1175/ 2010JAS3608.1.

Solomon, S., D. Qin, M. Manning, Z. Chen, M. Marquis, K. Averyt, M. Tignor, and H. L. Miller Jr., Eds., 2007: Climate Change 2007: The Physical Science Basis. Cambridge University Press, 996 pp.

SPARC CCMVal, 2010: SPARC report on the evaluation of chemistry-climate models, V. Eyring, T. G. Shepherd, and D. W. Waugh, Eds., SPARC Rep. 5, WCRP-132, WMO/TDNo. 1526, 434 pp. [Available online at http://www. sparc-climate.org/publications/sparc-reports/sparc-report-no5/.]

Stocker, T. F., and Coauthors, Eds., 2014: Climate Change 2013: The Physical Science Basis. Cambridge University Press, 1535 pp.

Stuber, N., M. Ponater, and R. Sausen, 2001: Is the climate sensitivity to ozone perturbations enhanced by stratospheric water vapor feedback? Geophys. Res. Lett., 28, 2887-2890, doi:10.1029/2001GL013000.

Wang, W.-C., M. P. Dudek, X. Liang, and J. T. Kiehl, 1991: Inadequacy of effective $\mathrm{CO}_{2}$ as a proxy in simulating the greenhouse effect of other radiatively active gases. Nature, 350, 573-577, doi:10.1038/350573a0.

WMO, 2011: Scientific Assessment of Ozone Depletion: 2010. Global Ozone Research and Monitoring Project Rep. 52, World Meteorological Organization, 516 pp. [Available online at http://www.esrl.noaa.gov/csd/assessments/ozone/2010/ report.html.] 